\title{
Las células de Langerhans en la inmunidad a leishmaniasis
}

\author{
Milena Zuluaga, Sara María Robledo \\ Programa de Estudio y Control de Enfermedades Tropicales, PECET, Corporación Académica para el \\ Estudio de Patologías Tropicales, Universidad de Antioquia, Medellín, Colombia.
}

En la respuesta inmune a parásitos del género Leishmania influyen múltiples factores entre los que se encuentran no sólo los relacionados con el parásito sino también aquéllos relacionados con el hospedero; de particular importancia es el tipo participante de célula presentadora de antígenos. En la piel, lugar donde el vector inocula el parásito, se encuentran las células de Langerhans que tienen como principal función servir como centinelas para la detección de microorganismos invasores. El estímulo que genera el microorganismo o las células circundantes induce la activación de las células de Langerhans, su maduración y migración hacia el tejido linfoide local (regional) donde presentan los antígenos a las células T para la posterior activación y diferenciación de subpoblaciones de células T específicas, responsables de la resolución de la infección o de la cicatrización. Se ha observado que durante la fase temprana de la infección con Leishmania hay muy pocas células T en el sitio de la infección lo cual sugiere que los macrófagos infectados tienen pocas probabilidades de encontrar allí células $\mathrm{T}$ con la especificidad requerida para eliminar el parásito y que, por tanto, son las células de Langerhans las que proporcionan la señal que activa las células $T$ específicas para Leishmania en los ganglios linfáticos locales que drenan de la lesión e inducen su migración al sitio de la lesión. En la presente revisión se abordan las principales características de las células de Langerhans, se hace especial énfasis en la participación en la respuesta inflamatoria cutánea y se presentan los hallazgos más relevantes del papel de estas células en el modelo de infección por parásitos del género Leishmania.

Palabras clave: células de Langerhans, células dendríticas, Leishmania, respuesta inmune.

\section{Role of Langerhans cells in the immunity of leishmaniasis}

Immune response induced against Leishmania parasites is influenced by several factors, one of the most important being the type of Antigen Presenting Cell (APC). Langerhans cells, a subpopulation of APC, are sentinel cells for detecting invader microorganisms; they reside in skin tissues at levels where the phlebotomine fly vector inoculates Leishmania parasites. Presence of microorganisms can induce activation of Langerhans cells, leading to their maturation and migration towards lymph nodes. There, Langerhans cells present antigens to $T$ cells for their subsequent activation and specific differentiation into effector cells. Early after a Leishmania infection, few $T$ cells have been observed at sites of infection, suggesting that infected macrophages have little opportunity to locate $T$ cells specific for elimination of Leishmania parasites. However, Langerhans cells may be the cells available to provide signals for the stimulation of parasite-specific T-cell responses in the lymph node and for inducing T-cell migration to the infected skin. Herein, the main characteristics of Langerhans cells are reviewed, with special emphasis on their participation in cutaneous inflammatory response. The role of these cells in infections caused by protozoan parasites of the Leishmania genus is discussed.

Key words: Langerhans cells, dendritic cells, Leishmania, immune response. 
La leishmaniasis en una enfermedad infecciosa de amplia distribución mundial; es endémica en, al menos, 88 países ubicados en zonas tropicales y subtropicales. En Colombia, la leishmaniasis se distribuye por todo el territorio nacional (con la excepción de San Andrés y Providencia) y se presenta en las zonas rurales y semiurbanas que poseen las condiciones ecoepidemiológicas favorables para su transmisión.

La enfermedad se produce por la infección con, al menos, 12 especies de parásitos intracelulares obligados del género Leishmania, de las cuales existen ocho en Colombia. Las diferencias que presentan las distintas especies en cuanto a características ecoepidemiológicas y clínicas hacen que se agrupen en dos subgéneros: el subgénero Leishmania ( $L$ ) cuyas especies se encuentran distribuidas tanto en el Viejo Mundo (Europa, Asia y África) como en el Nuevo Mundo (América) y el subgénero Viannia (V) cuyas especies están restringidas al Nuevo Mundo.

En América, los parásitos se transmiten a partir de un reservorio animal o humano por la picadura de insectos hembra hematófagas del género Lutzomyia (1-3) y producen las formas clínicas conocidas como leishmaniasis cutánea (LC) cuando afecta la piel, leishmaniasis mucosa (LM) cuando afecta los tejidos mucosos y leishmaniasis visceral (LV) cuando afecta la médula ósea, el hígado y el bazo. A su vez, la LC se puede presentar en forma localizada (LCL) o difusa (LCD) y puede, además, afectar en forma simultánea piel y mucosas, enfermedad que se conoce como leishmaniasis mucocutánea (LMC) (4). En Colombia, la leishmaniasis se presenta en todas sus formas clínicas siendo la LCL la más frecuente.

Por su parte, Leishmania (V) panamensis es la especie del parásito responsable del $95 \%$,

\footnotetext{
Correspondencia:

Sara María Robledo, Programa de Estudio y Control de Enfermedades Tropicales, Corporación Académica para el Estudio de Patologías Tropicales, Universidad de Antioquia, Calle 62 No. 52-59 SIU, Laboratorio 632, Medellín, Antioquia. Teléfono: 210 6503; fax: 2106502 srobledo@guajiros.udea.edu.co
}

Recibido: 12/11/03; aceptado: 13/07/04 aproximadamente, de los casos que se registran en el país; produce principalmente LCL y, también, casos de LCD y $\operatorname{LM}(5,6)$. Además, L. (V) panamensis se caracteriza por producir infecciones crónicas y persistentes y está implicada también en la presentación de recaídas, reinfecciones y diseminación a mucosas $(7,8)$.

El problema de la leishmaniasis se complica cada vez más puesto que la prevalencia de la enfermedad viene en aumento (de 6.500 casos que se registraron en el 2002 a cerca de 10.000 diagnosticados en el 2003) (9). Por otro lado, la leishmaniasis ya no se considera una enfermedad rural que afecta principalmente a hombres en edad laboral activa y se ha convertido en una enfermedad de transmisión doméstica rural y semiurbana, donde toda la familia, y especialmente los niños, representan la población de mayor riesgo (10) y, desde hace algunos años, se viene demostrando el proceso de urbanización de la enfermedad $(11,12)$.

El trauma que se produce en el hospedero vertebrado por la picadura del insecto vector infectado con el parásito, induce una respuesta inflamatoria que involucra la migración de diferentes células, principalmente macrófagos y linfocitos, hacia el sitio del trauma a fin de reparar el tejido dañado e iniciar el proceso de cicatrización (13). Dentro del hospedero mamífero, los promastigotes inoculados por el vector invaden las células del sistema de células fagocíticas mononucleares (monocitos/macrófagos) presentes en el sitio de la infección al igual que las células reclutadas durante la respuesta inflamatoria o que son fagocitados por ellas (14). Una vez intracelulares, los promastigotes se transforman en amastigotes para así sobrevivir y multiplicarse dentro del fagolisosoma de su célula hospedera (15-17).

El fenotipo clínico, es decir, el desarrollo de enfermedad o no y, por ende, la aparición de lesiones luego de la infección con el parásito, depende en gran parte de la respuesta inmune desencadenada por el hospedero para tratar de eliminar al parásito inoculado; a su vez, los mecanismos inmunológicos inducidos por el parásito varían según la especie de Leishmania 
implicada en el proceso infeccioso, la forma clínica de la enfermedad y la cronicidad de la misma.

Los estudios realizados tanto in vitro como in vivo en el modelo murino de infección por Leishmania (L) major (una especie de Leishmania presente solamente en el Viejo Mundo) han demostrado que la resolución de la infección o enfermedad depende de los mecanismos de respuesta inmune mediada por células Th (CD4+) y sus productos; las células efectoras Th1 son las que se asocian con el control de la infección o con una respuesta cicatrizante a través de la producción de interferón gamma (IFN- $\gamma$ ) y la posterior producción de factor de necrosis tumoral alfa (FNT- $\alpha$ ) por parte de los macrófagos activados debido a la acción del IFN$\gamma$; por su parte, las células efectoras Th2 se asocian con el desarrollo de formas graves de la enfermedad por medio de la producción de interleucina (IL) 4 e IL-10 $(13,18,19)$.

A diferencia de lo observado en la leishmaniasis murina experimental, en la leishmaniasis humana la respuesta no es polarizada y se observa, en cambio, un patrón con presencia de citocinas tanto Th1 como Th2, donde el predominio de citocinas propias del perfil Th2 se correlaciona con la persistencia del parásito y con la progresión de la enfermedad, mientras que el control efectivo de la infección y, por tanto,la presentación clínica menos grave ocurre cuando hay predominio de citocinas propias del perfil Th1 que tienen como función principal la activación del macrófago y la subsiguiente muerte del parásito en el interior de su célula hospedera (20-24).

Sin embargo, es importante tener en cuenta que la activación del macrófago se acompaña también de la producción de citocinas proinflamatorias que favorecen un estado de inflamación crónica, con la posterior necrosis del tejido, por lo que el desarrollo de la lesión puede ser el resultado, en parte, de la activación excesiva de la respuesta inmune activadora del macrófago y de la no activación, o activación inadecuada, de una respuesta inmune reguladora por parte del parásito. Los factores o mecanismos que dirigen la diferenciación y activación de las células Th1 al igual que los mecanismos o factores que regulan su activación están en proceso de ser identificados.
Entre los diferentes factores que participan y definen el desarrollo de una respuesta de células Thacia Th1 o Th2 juega un papel muy importante el tipo de célula presentadora de antígeno (CPA) involucrada durante la interacción de la célula $T$ con el antígeno (Ag) específico $(25,26)$. Hasta hace poco se aceptaba que el macrófago cumplía un papel central en la patogénesis de la leishmaniasis al funcionar no sólo como célula hospedera por excelencia, sino también como CPA a células T específicas y como célula efectora responsable de la muerte intracelular del parásito y, por lo tanto, el macrófago era la célula responsable de mediar la estimulación de las células T específicas para que, a su vez, las citocinas liberadas por las células $\mathrm{T}$ activadas regularan el potencial microbicida del macrófago (la célula hospedera) y limitaran la propagación de los parásitos $(27,28)$.

Dado que durante la fase temprana de la infección con Leishmania hay muy pocas células $T$ en el sitio de infección (29), los macrófagos infectados que están expresando antígenos del parásito tienen muy poca probabilidad de encontrarse con células $T$ que tengan la especificidad necesaria para inducir una respuesta inmune efectiva contra el parásito; se requiere una señal que sea capaz de activar las células T específicas en los órganos linfoides e inducir su migración hacia el sitio de la lesión. Lo anterior sugiere que los macrófagos no son suficientes para inducir y modular la respuesta inmune mediada por células contra Leishmania y que se necesita, entonces, la ayuda de células vecinas con potente capacidad estimuladora de la respuesta inmune específica de células $T$ como lo son las células dendríticas (30).

Las células dendríticas constituyen una población de células de origen hematopoyético presentes en diferentes tejidos linfoides y no linfoides (principalmente, piel, mucosas y ganglios linfáticos) como células inmaduras (31). Actualmente, se reconocen a las células dendríticas como células reguladoras esenciales tanto de la respuesta inmune innata como de la respuesta inmune adquirida ya que poseen características fenotípicas y funcionales que las convierten en excelentes células presentadoras de antígenos. Entre estas características sobresale su capacidad para internalizar 
antígenos propios y no propios (ya sean particulados o solubles), degradarlos en su interior y asociarlos a moléculas del complejo mayor de histocompatibilidad permitiendo el reconocimiento del antígeno por parte de las células $\mathrm{T}$ y la posterior activación y diferenciación de estas células T para la producción de citocinas que, en última instancia, son las encargadas de dirigir los mecanismos efectores de la respuesta inmune.

Las células dendríticas tienen la capacidad de estimular eficientemente células $T$ no sensibilizadas (32), propiedad que no comparten con otras células presentadoras de antígeno como, por ejemplo, las células $B$ las cuales pueden estimular tanto células $T$ no sensibilizadas (33-35) como también células $T$ de memoria pero con baja eficiencia (36). Por tanto, las células dendríticas participan no sólo en la protección de los tejidos periféricos de la invasión por microorganismos patógenos sino también en la inducción de la tolerancia inmunológica. Estas observaciones sugieren que las células dendríticas, que son potentes estimuladoras de respuesta de células T específicas para antígenos y muy abundantes en la piel, son las células que proporcionan la señal que activa las células T específicas para Leishmania en los ganglios linfáticos drenantes de la lesión e inducen la migración de las células T específicas al sitio de la lesión (37).

Gracias a las nuevas metodologías disponibles actualmente para el cultivo y diferenciación in vitro de las células dendríticas a partir de diferentes células precursoras presentes tanto en la médula ósea como en la sangre periférica, se reconoce a las células dendríticas como una familia de células en la cual cada subpoblación ejerce un control sobre un área diferente de la respuesta inmune (31). Es así como algunas subpoblaciones están encargadas de la activación de las células $T$ mientras que otras subpoblaciones están cumpliendo su función en la generación de una respuesta mediada por anticuerpos (38) o potenciando la respuesta citotóxica mediada por células asesinas naturales (NK) (39).

Además, otras subpoblaciones participan en el mantenimiento de la tolerancia inmunológica al participar en la eliminación de células $T$ autorreactivas (40). Al parecer, la capacidad que tienen las células dendríticas de inducir diferentes tipos de respuesta inmune mediada por células $T$ depende de su linaje, su estado de maduración y las señales de activación (31). Sin embargo, gran parte de los aspectos fundamentales de la biología de las células dendríticas se desconoce todavía.

Entre las diferentes subpoblaciones de células dendríticas se encuentran las células de Langerhans que se localizan en la piel (epidermis) y tienen como principal función servir como centinelas para la detección de microorganismos invasores (41). El estímulo generado por el microorganismo o por las células circundantes induce la activación y la maduración de las células de Langerhans y su migración hacia el tejido linfoide local donde presentan los antígenos a las células $T$ para la posterior activación y diferenciación de subpoblaciones de células $T$ específicas $(42,43)$.

Dado que la leishmaniasis cutánea es una enfermedad producida por la inoculación intradérmica del parásito por parte del insecto vector, es posible pensar que las células de Langerhans tienen una participación crítica no sólo durante el proceso inflamatorio al expresar moléculas $\mathrm{CMH}$ clase II y moléculas de adhesión necesarias para la migración y retención de las células inflamatorias, sino también en la iniciación de una respuesta específica de antígenos. Sin embargo, aún se desconoce como es la participación de las células de Langerhans en la activación de la respuesta protectora contra la infección por parásitos del género Leishmania (44).

Por lo tanto, en la presente revisión se discuten las características generales y principales de las células dendríticas para luego profundizar en las células de Langerhans, con especial énfasis en su participación en la respuesta inflamatoria cutánea. Además, se presentan los hallazgos más relevantes acerca del papel de las células de Langerhans en el modelo de infección por Leishmania spp. La revisión se hizo con base en la lectura de 108 artículos recopilados por los autores en la búsqueda en la base de datos PubMed (1978-2004) y seleccionados según el tema: leishmaniasis, biología de las células dendríticas y las células de Langerhans, al igual que artículos que muestran evidencias del efecto 
de la interacción de las células de Langerhans con los parásitos de Leishmania spp.

\section{Ontogenia, fenotipo y función de las células dendríticas}

Las células dendríticas son una familia de células con propiedades inmunológicas importantes (31) y están ampliamente distribuidas como células inmaduras en epitelios y mucosas (piel, estómago, tracto genitourinario y pulmón), en espacios intersticiales de diferentes órganos (por ejemplo, hígado, riñón y corazón) y en órganos linfoides (45). Las células dendríticas son células hematopoyéticas derivadas a partir de una célula madre pluripotencial presente en la médula ósea y, según sea el microambiente de citocinas que rodea su desarrollo, da origen a células precursoras de células dendríticas de tipo mieloide o linfoide (46) las cuales difieren no sólo en su fenotipo sino también en su localización anatómica y en su función.

Las células dendríticas de tipo mieloide se encuentran inicialmente en los tejidos y mucosas como células dendríticas inmaduras, caracterizadas por una baja expresión de las moléculas coestimuladoras CD40, CD80 y CD86 y abundantes moléculas $\mathrm{CMH}$ en los compartimentos intracelulares (47). Además, expresan el receptor para el factor estimulante de colonias de granulocitos y monocitos (GM-CSF); como células inmaduras, poseen una alta capacidad de endocitosis y responden rápidamente a los estímulos generados por las citocinas inflamatorias y los productos microbianos, estímulos que las activan e inducen su maduración; luego de que ocurre la captura del antígeno, las células dendríticas maduran y migran a los órganos linfoides (principalmente, ganglios, bazo y placas de Peyer) para iniciar la presentación antigénica a las células T no sensibilizadas (48); como células dendríticas maduras, pierden la capacidad de endocitar antígenos y aumentan la expresión de las moléculas coestimuladoras y $\mathrm{CMH}$ en la membrana celular (47). Estas células dendríticas de tipo mieloide se pueden aislar como células maduras a partir de sangre periférica, ganglios linfáticos, hígado, médula ósea, cordón umbilical y timo (49) o se pueden diferenciar a partir de monocitos y células precursoras mieloides CD34+ cultivadas en presencia de GMCSF e IL-4 (50-52).

Por su parte, las células dendríticas de tipo linfoide se localizan en las zonas de las células T en el bazo y en la médula del timo y cumplen un papel en los fenómenos de regulación y tolerancia inmunológica ya que presentan principalmente péptidos derivados de antígenos propios y tienen la capacidad de regular a las células $T$ reactivas al producir IL-10 o inducir apoptosis vía Fas ligando (FasL) $(48,53,54)$; los progenitores de las células dendríticas linfoides se caracterizan porque carecen de los antígenos mieloides CD11c, CD11b, CD13, CD33 y CD45RO, expresan altos niveles de la cadena $\alpha$ del receptor para IL-3 (citocina necesaria para su diferenciación), no expresan el receptor para GM-CSF (55) y expresan bajos niveles de la molécula CD4; cuando maduran, expresan la molécula CD8 (49).

Actualmente, es posible diferenciar las células dendríticas de tipo linfoide y mieloide por la expresión de la molécula CD8a que se expresa como homodímero en las células dendríticas de tipo linfoide y está ausente en las células dendríticas de tipo mieloide (56).

Las células dendríticas tienen la capacidad de evolucionar de células dendríticas inmaduras (con una alta capacidad para capturar antígenos propios y no propios) a células dendríticas maduras (con una alta capacidad de presentar antígenos y activar a las células $T$ no sensibilizadas). Además, las células dendríticas expresan abundantes moléculas $\mathrm{CMH}$ clase I y II, moléculas coestimuladoras como CD40,CD80 y CD86 y producen citocinas como IL-12 e IL-4 (46), propiedades que las convierten en potentes células presentadoras de antígenos y, por tanto, su participación es crucial no sólo en la respuesta inmune primaria sino también en la inducción de la tolerancia inmunológica.

Sin embargo, el tipo de respuesta inmune mediada por células $T$ que es inducida por las células dendríticas (inmunidad vs. tolerancia o respuesta Th1 vs. Th2) varía dependiendo del linaje específico de la célula dendrítica (mieloide o linfoide), del estado de maduración (maduras o 
inmaduras) y de las señales recibidas para su activación como la entrada de antígenos extraños y la producción de IL-12 por células presentes en el tejido afectado.

El estímulo que se genera por la entrada de un microorganismo patógeno hace que las células dendríticas inmaduras sean atraídas a sitios de inflamación y ocurra allí la internalización del antígeno ya sea por mecanismos de macropinocitosis (57) o de fagocitosis mediada por receptores presentes en su membrana (58). Luego de la captura del antígeno, las células dendríticas presentes en los tejidos se activan por el efecto de los productos bacterianos, de citocinas como la IL-1b, el GM-CSF y el TNF- $\alpha$ y de otros mediadores solubles producidos por las células inflamatorias (59).

Con la activación se reduce la capacidad de las células dendríticas para internalizar antígenos pero se aumenta la expresión de moléculas $\mathrm{CMH}$ y moléculas coestimuladoras, ocurre la producción de citocinas como la IL-12 (60) y se adquiere la capacidad para migrar a través de los tejidos hacia órganos linfoides locales (61). Una vez en el tejido linfoide, la célula dendrítica interactúa con las células Th principalmente, debido a la alta expresión de moléculas $\mathrm{CMH}$ clase Il y moléculas coestimuladoras (60). La interacción de la célula dendrítica con la célula Th favorece el desarrollo de células Th1 por medio de la producción de grandes cantidades de IL-12 por la célula dendrítica, o de Th2 por medio de la producción de un factor que todavía no se ha caracterizado $(30,62)$.

Aunque no es el objeto de esta revisión, es importante mencionar que en los órganos linfoides las células dendríticas también pueden interactuar directa o indirectamente con las células $B$ y participar en la generación de una respuesta primaria de anticuerpos (63) y, además, interactuar con células NK y participar en los procesos de apoptosis (64).

Entre las diferentes subpoblaciones de células dendríticas se encuentran las células de Langerhans (65) que son células dendríticas presentes en la epidermis, un tejido especializado no sólo en cubrir el cuerpo y protegerlo de daños procedentes del medio exterior, sino también en participar en la respuesta inmune frente a microorganismos invasores y cuyas características fenotípicas y funcionales al igual que su papel en las infecciones por Leishmania se discuten a continuación.

\section{Las células de Langerhans: centinelas importantes de la piel}

Las células de Langerhans, descritas en 1868 por Paul Langerhans, son células dendríticas presentes en la dermis reticular y, por tanto, juegan un papel fundamental en la inmunidad cutánea ya

Cuadro 1. Marcadores fenotípicos y funcionales de las CL versus DC y monocitos.

\begin{tabular}{llll}
\hline Expresión marcador/función & DC & LC & Monocito \\
\hline CD1a & + & + & - \\
CD8a & + & + & - \\
CD11b & + & + & + \\
CD14 & - & - & + \\
CD40 & +++ & +++ & + \\
CD80 & + & - & - \\
CD83 & + & + & + \\
CD86 & +++ & +++ & - \\
CD207 (Langerina) & - & + & + \\
CMH-I & ++++ & ++++ & - \\
CMH-II & +++ & +++ & Sí \\
Gránulos de Birbeck & - & + & No \\
Esterasas & Sí & No & Sí \\
E-Cadherina & No & Sí & No \\
Receptores para manosa-fucosa & Sí & No & Sí \\
Activación primaria de células T & Sí & & \\
\hline
\end{tabular}


que son potentes estimuladores de la respuesta específica mediada por células $T$, restringida por el CMH. Las células de Langerhans se encuentran preferiblemente en la epidermis y constituyen alrededor del $3 \%$ del total de las células presentes en este tejido (66-68).

En los últimos cinco años se ha progresado mucho en la caracterización de la morfología y función de las células de Langerhans gracias a la disponibilidad de técnicas para su cultivo y diferenciación in vitro y de diversos marcadores específicos de membrana que permiten estudiarlas con detalle (69-71). Estas células poseen prolongaciones citoplasmáticas características conocidas como dendritas y organelos citoplasmáticos denominados gránulos de Birbeck (72); comparten algunas características fenotípicas con los macrófagos como son: la presencia de ATPasas y esterasas inespecíficas, la expresión de receptores de membrana tipo manosa-fucosa (MFR), receptores Fc (FcR) o el receptor para la proteína C3 (CR3) y la expresión de moléculas $\mathrm{CMH}$ clase II (cuadro 1).

La maduración funcional de las células de Langerhans se acompaña de cambios en el fenotipo que incluyen el aumento en la expresión de moléculas $\mathrm{CMH}$ clase II y la pérdida gradual de los gránulos de Birbeck. La maduración es inducida por la acción de productos microbianos o citocinas tales como IL-1b, IL-6, IL-8, GM-CSF, TNF- $\alpha$ y el factor de crecimiento tumoral-beta (TGF- $\beta$ ) producidas por queratinocitos y otras células que ocasionan la migración de la célula y la presentación de péptidos antigénicos asociados con las moléculas $\mathrm{CMH}$ clase II $(41,73,74)$.

\section{Ontogenia y linaje de las células de Langerhans}

Como todas las células del sistema inmune, las células de Langerhans se originan de la médula ósea. Durante la ontogenia, los precursores de las células de Langerhans pueblan la epidermis y adquieren moléculas inmunológicamente importantes como las molécula $\mathrm{CMH}$ clase II y Langerina/CD207 (66). Con respecto al linaje de las células de Langerhans, la mayoría de los hallazgos fenotípicos apuntan a un origen mieloide ya que expresan marcadores característicos de este linaje como son CD11b y CD33 (75). Además, los monocitos derivados de sangre periférica cultivados en presencia de GM-CSF, IL-4 y TGF$\beta$ dan origen a células dendríticas con el fenotipo característico de las células de Langerhans (76).

Por otro lado, existen algunas evidencias que sugieren un origen linfoide para las células de Langerhans puesto que las células precursoras linfoides bien definidas inyectadas en ratones pueden originar células de Langerhans $(66,77)$ o, como se ha observado recientemente, las células de Langerhans pueden regular en forma positiva la molécula CD8a (un marcador asociado con células precursoras linfoides) durante los procesos de migración y maduración (78); sin embargo, la posibilidad de diferenciar células dendríticas positivas para la molécula CD8a a partir de una célula completamente definida como progenitor mieloide (79) sugiere que el origen linfoide propuesto para las células de Langerhans debe ser replanteado. Estas evidencias muestran el potencial de ambos progenitores para originar células de Langerhans in vitro, y hace necesario definir lo que ocurre in vivo.

\section{Funciones de las células de Langerhans}

Vigilancia de la epidermis y transporte de antígenos a órganos linfoides periféricos

Las células de Langerhans se reconocen como células centinelas ya que están expuestas al medio ambiente de la epidermis donde múltiples factores pueden alterar su homeostasis y generar señales de alarma que promuevan la movilización de la células de Langerhans desde la epidermis al tejido linfoide transportando la información pertinente. Estos estímulos pueden ser agentes químicos tipo alergenos de contacto, agentes físicos como la radiación ultravioleta y agentes biológicos como productos de virus, bacterias, hongos y parásitos (80). Una vez la célula de Langerhans se estimula por cualquiera de estos agentes inicia el transporte del antígeno desde la epidermis hasta el ganglio linfático. Entre los mediadores responsables del proceso de migración se incluye el TNF- $\alpha(59,81)$ que se considera el principal mediador de dicho proceso toda vez que la inyección de TNF- $\alpha$ en la dermis del ratón causa una acumulación de células 
dendríticas en los ganglios linfáticos que drenan esta región entre 8 y 24 horas después de ocurrida la sensibilización (82).

\section{Producción de citocinas}

Durante la activación de las células T se generan diferentes señales intracelulares que conducen a la producción de citocinas de tipo Th1 (IFN- $\gamma$ ) o Th2 (IL-4, IL-5, IL-6 o IL-10) por parte de las células T. Además, se producen otras señales coestimuladoras por parte de la CPA que permiten la activación óptima de la célula $T$, entre las cuales se incluyen las diferentes citocinas producidas por la CPA y que se mencionan a continuación.

IL-1b: la familia de la IL-b la conforman tres péptidos: IL-1a, IL-1b e IL-1 ra; la IL-1b es una de las citocinas más importantes ya que en ausencia de IL-1b no se produce respuesta inmune adquirida. La acumulación temprana de ARNm de IL-1b luego del estímulo antigénico constituye una de las primeras manifestaciones de la activación de la células de Langerhans; la IL-1b es crítica para la activación del linfocito $T$ pues contribuye en la respuesta y generación de la IL-2 por parte del linfocito $T$ y produce efectos proinflamatorios sobre distintos tipos celulares, como es el caso de las células endoteliales en las cuales la activación induce la expresión de moléculas de adhesión como la molécula de adhesión intercelular 1 (ICAM-1) (83); la IL-1b puede aumentar la proliferación de las células B e incrementar la síntesis de inmunoglobulinas, induce la síntesis adicional de otras citocinas como FNT- $\alpha$, IL-6, GM-CSF y de otros factores como prostaglandina $\mathrm{E} 1\left(\mathrm{PGE}_{1}\right)$ y leucotrieno $\mathrm{B} 4$ (LKT4) $(59,84,85)$.

FNT- $\alpha$ : una vez producido el FNT- $\alpha$, se localiza en la membrana de la célula pero la forma activa la constituye el FNT- $\alpha$ soluble. La mayor actividad proinflamatoria del FNT- $\alpha$ la ejerce por medio de la interacción con las células endoteliales para la inducción de expresión de moléculas de adhesión como el ICAM-1 y la molécula de adhesión celular vascular 1 (VCAM-1) (86); esta citocina activa los linfocitos $\mathrm{B}$ y los monocitos, aumenta la capacidad de los monocitos para producir mediadores inflamatorios tipo IL-6 e IL-8 y es un potente activador de neutrófilos para adherencia, quimiotaxis y degranulación. El FNT- $\alpha$ es uno de los principales estímulos que ocasionan el transporte del antígeno desde la epidermis hasta el ganglio linfático $(82,85)$.

IL-6: las células de Langerhans son la principal fuente de IL-6 en epidermis ya que esta citocina es producida en forma constitutiva por células de Langerhans no sensibilizadas. La IL-6 constituye un factor importante en la coestimulación del linfocito T; participa, además, en la diferenciación de los linfocitos $B$ a células plasmáticas maduras productoras de anticuerpos, es un factor activador de neutrófilos y permite la maduración de células progenitoras en la médula ósea $(87,88)$.

IL-12: la IL-12 bioactiva está compuesta de la subunidades p35 y p40 y es una citocina clave del sistema inmune innato; es producida por células presentadoras de antígenos profesionales como las células dendríticas, macrófagos y en menor cantidad por linfocitos B; las células dendríticas son más potentes e importantes productoras de IL-12. En la fase temprana de la inmunidad innata, la IL-12 actúa sobre las células NK y las células T CD8+ e inducen la producción de IFN- $\gamma$ el cual, a su vez, activa macrófagos potenciando su actividad microbicida y su capacidad para fagocitar y producir oxido nítrico. Además, el estímulo con IL-12 potencia las actividades citolíticas de las células NK y las células T CD8+ para eliminar células infectadas con patógenos intracelulares y tumores malignos. Por esta razón, la IL-12 constituye el centro de múltiples líneas de

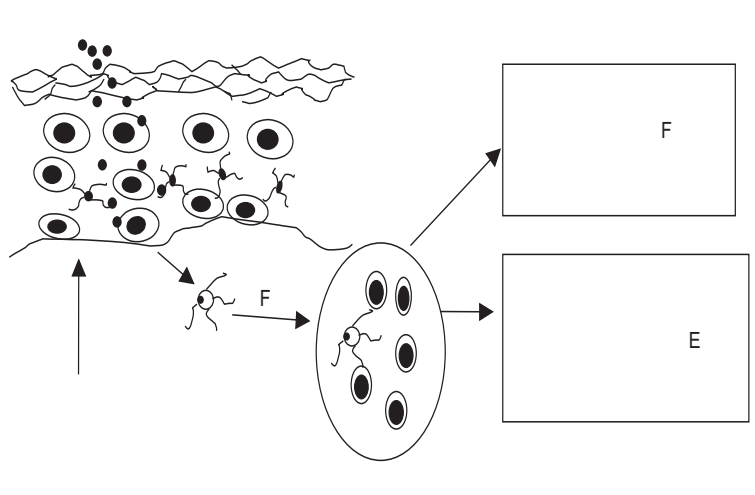

Figura 1. Representación esquemática del ciclo de vida de las células de Langerhans y su función como células presentadoras de antígeno a través de la ruta de la piel. 
investigación en cáncer y diferentes enfermedades infecciosas entre las que se encuentra la leishmaniasis. La producción de IL-12 por las células de Langerhans en respuesta a los parásitos del género Leishmania se abordará más adelante en esta revisión $(89,90)$.

\section{Presentación de antígenos a células $T y$ activación de la respuesta inmune específica}

Al igual que las demás subpoblaciones de células dendríticas, las células de Langerhans tienen la capacidad de internalizar antígenos, activarse y madurar, migrar a órganos linfoides, presentar antígenos a células $T$ no sensibilizadas y de memoria y activar la respuesta inmune adquirida; sin embargo, las propiedades funcionales de las células de Langerhans in vitro también dependen del estado de diferenciación. Se ha demostrado que las células de Langerhans recién aisladas pueden procesar antígenos nativos para presentarlos a células $T$ previamente sensibilizadas pero tienen poca capacidad de activar células $T$ en reposo, mientras que durante la fase terminal del cultivo las células de Langerhans pierden su capacidad de procesar antígenos pero adquieren un potencial único para estimular las células $T$ no sensibilizadas y activar la respuesta inmune primaria (28).

En los últimos años se han realizado numerosos estudios con el fin de emplear las células de Langerhans de manera terapéutica como moduladoras de la respuesta inmune ya sea para generar una respuesta inmune, para aumentarla o para suprimirla. En el tratamiento del melanoma, varios trabajos realizados tanto en modelos animales como en humanos, han documentado la eficacia del empleo de células de Langerhans obtenidas del paciente y estimuladas in vitro con proteínas intactas o péptidos derivados del tumor $y$, que al ser implantadas nuevamente en el paciente, son capaces de generar una respuesta inmune antitumoral específica (91).

\section{Participación en la respuesta inflamatoria epidérmica}

Las células de Langerhans expresan el receptor de alta afinidad para la IgE conocido como FceRI (92) y, a través de esta molécula, pueden capturar antígenos para su posterior presentación e inducción de una respuesta inmune. Se ha demostrado que la expresión del FceRI en monocitos y células de Langerhans se regula en forma positiva a través del factor nuclear $\mathrm{kB}$ (NF$k B)$, un factor de transcripción que regula la expresión de genes esenciales para la respuesta inflamatoria y la diferenciación y función de las células dendríticas (93). Los eventos de señalización tardía que involucran el NF-kB favorecen la liberación de citocinas y quimiocinas proinflamatorias, citocinas polarizadoras de la respuesta Th y de factores apoptóticos. Se ha demostrado que la activación de las células de Langerhans a través de la interacción IgE-FceRI induce la síntesis y liberación de FNT- $\alpha$, la proteína quimiotáctica de monocitos-1 (MCP-1), IL-10 , IL12 e IL-16 (94,95), citocinas que contribuyen al reclutamiento y activación de células dendríticas, linfocitos $T$ y eosinófilos. Por lo tanto, la captura de antígenos por parte de las células de Langerhans a través del FceRI constituye un posible puente entre la respuesta inflamatoria celular. Así mismo, la respuesta inflamatoria mediada por $\lg \mathrm{E}$ y la activación de las células de Langerhans a través de NF-kB representa un mecanismo por el cual el FceRI expresado en monocitos y células dendríticas puede controlar las reacciones inflamatorias $(96,97)$.

\section{Papel de las células de Langerhans en la infección por Leishmania spp.}

Las evidencias que sustentan el papel de las células de Langerhans en las enfermedades infecciosas y, concretamente, en las infecciones por Leishmania spp. han aumentado considerablemente durante los últimos 10 años. Como se mencionó anteriormente, se ha establecido que las células de Langerhans juegan un papel central en la iniciación y regulación de la respuesta inmune contra diferentes microorganismos, inclusive parásitos protozoarios del género Leishmania, ya que estas células son mucho más eficientes que los macrófagos en la presentación de antígenos de Leishmania a las células $T$ y tienen la habilidad única de retener antígenos del parásito en forma inmunogénica por periodos prolongados (98). Al parecer, la internalización de antígenos de Leishmania por las células de Langerhans ocurre por medio de 
CR3 ya que se ha observado inhibición de la fagocitosis de promastigotes de $L$. (L) major por parte de las células de Langerhans cuando se bloquea el CR3 con anticuerpos específicos (58).

Por otro lado, se sugiere que la fagocitosis de antígenos de $L$. ( $L$ ) major aumenta la biosíntesis de moléculas $\mathrm{CMH}$ clase II durante la diferenciación de células de Langerhans ya que las moléculas del $\mathrm{CMH}$ sintetizadas de novo están asociadas con la vacuola parasitófora de células de Langerhans infectadas (99) lo que puede explicar la eficiencia en la presentación de antígenos de Leishmania por la células de Langerhans. También se ha observado que la expresión de moléculas coestimuladoras, como B7-1 (CD80), en las células de Langerhans se regula en forma negativa luego del contacto con parásitos de Leishmania y esta regulación se asocia con la disminución en la producción de citocinas como IL-4 y la activación de células T evidenciada por la producción de IFN- $\gamma$ en cocultivos in vitro (100).

En cuanto a la capacidad de migración de las células de Langerhans luego de la exposición a antígenos de Leishmania, se ha evidenciado que el lipofosfoglicano del parásito puede inhibir la migración de las células de Langerhans y, de esta forma, modular sus funciones inmunoestimuladoras las cuales requieren de la llegada de las células de Langerhans a los órganos linfoides (101). Sin embargo, la migración de las células de Langerhans infectadas con Leishmania también puede ser modulada por citocinas producidas durante la respuesta inflamatoria tales como el TNF- $\alpha$ que aumenta o favorece la migración de dichas células, o la IL-1b que la disminuye (59). Una vez las células de Langerhans migran desde el sitio de la infección hacia el ganglio linfático, la expresión de antígenos del parásito ocurre en las células de Langerhans pero no en los macrófagos (102).

Por otro lado, se ha observado que las células de Langerhans presentes en los ganglios linfáticos tienen la capacidad de estimular in vitro células $T$ previamente activadas y, más aún, son capaces de estimular in vivo células $T$ no activadas que, luego, median una reacción de hipersensibilidad retardada específica del parásito (37). Se ha estudiado también la capacidad de las células de Langerhans para mediar la resistencia a infección por $L$. (L) major in vivo. La aplicación intravenosa de células de Langerhans estimuladas con antígenos de $L$. (L) major in vitro induce la protección en ratones susceptibles (cepa BALB/ c) cuando se les reta con parásitos de $L$. (L) major, dicha protección no se observó cuando los ratones se trataron con macrófagos estimulados en iguales condiciones (103). Esta observación se puede explicar por el hecho de que las células de Langerhans, a diferencia de los macrófagos, mantienen números bajos de organismos intracelulares ya que su objetivo no es la diseminación del parásito sino realizar una eficiente presentación antigénica (58).

\section{Producción de IL-12 por las células de Langerhans en respuesta a la infección por Leishmania spp.}

Los numerosos estudios realizados en el modelo murino de infección por $L$. (L) major sugieren que la producción de IL-12 es crítica para el desarrollo de una respuesta inmune tipo Th1 luego de la infección por Leishmania. Los estudios in vitro demuestran que las células dendríticas expuestas a infección por Leishmania, a diferencia del macrófago, producen abundante IL-12 (104); sin embargo, es poca la información que se tiene sobre la producción de esta citocina por las células de Langerhans infectadas con Leishmania. Las evidencias hasta ahora recopiladas apuntan a que existe una producción de IL-12p40 en las horas tempranas posinfección (18 horas) de células de Langerhans de ratones susceptibles (cepa BALB/ c) y resistentes (cepa C57BL/6) a infección por $L$. (L) major y una liberación de pequeñas cantidades de IL-12p70 más tardíamente (72 horas) en ambas cepas; sin embargo, una estimulación adicional con IFN- $\gamma$ o anti-CD40 induce la liberación de más IL-12p70 en los ratones susceptibles que en los resistentes. Además, se ha observado que esta producción de IL-12 por células de Langerhans infectadas puede ser regulada por IL-4 ya que el tratamiento con IL-4 disminuye fuertemente la producción de IL-12p40 por las células de Langerhans de ratones susceptibles $(105,106)$. Estas observaciones sugieren que la células de 
Langerhans más que el macrófago tiene un papel activo en la presentación antigénica y en la activación de células T específicas del parásito y que la regulación que ejerce el microambiente de citocinas sobre las células de Langerhans tiene una fuerte repercusión sobre el curso de la enfermedad.

\section{Modelo propuesto de interacción entre células de Langerhans y Leishmania spp.}

En las infecciones humanas por Leishmania y, menos aún, en las producidas por parásitos pertenecientes al subgénero Viannia, no es claro aún cuál o cuáles son los factores que dirigen la activación de células Th y su posterior diferenciación en células Th1 y Th2. Algunos de los trabajos de nuestro grupo han mostrado que la exposición in vitro de células mononucleares humanas (linfocitos y monocitos) a promastigotes de $L$. (V) panamensis disminuye la expresión de la molécula CD69, evaluada por citometría de flujo, lo cual sugiere la no activación temprana de dichas células luego de la infección. Por otro lado, al evaluar la expresión de moléculas $\mathrm{CMH}-\mathrm{I}$ y II por citometría de flujo en monocitos y células dendríticas obtenidas a partir de sangre periférica e infectados in vitro con promastigotes de $L$. (V) panamensis se observó que dicha expresión disminuye, en términos generales, en los monocitos y aumenta en las células dendríticas. La intensidad media de fluorescencia (IMF) para la molécula $\mathrm{CMH}-\mathrm{I}$ pasó de 2,4 en los monocitos expuestos al parásito a 1,0 luego de la exposición. Para la molécula CMH-II, la IMF fue de 4,0 en los monocitos no expuestos y de 3,3 en las células expuestas. Por el contrario, en las células dendríticas diferenciadas en presencia de GM-CSF e IL-4 a partir de monocitos de sangre periférica humana, la IMF para la molécula $\mathrm{CMH}$-I pasó de 174,0 en las células dendríticas no expuestas a 431,0 luego de la infección; igualmente, la IMF para la molécula $\mathrm{CMH}-\mathrm{Il}$ pasó de 28,0 en las células dendríticas no infectadas a 122,0 luego de la infección (datos no publicados). Estos hallazgos argumentan a favor del importante papel que tienen las células dendríticas como células presentadoras de antígenos en el curso de la infección por Leishmania spp. Sin embargo, al comparar la expresión de estas moléculas $\mathrm{CMH}$ en pacientes con LCL e individuos asintomáticos no se observan diferencias sustanciales lo que sugiere que otros mecanismos participan en la resolución de la infección o el desarrollo de la enfermedad.

Con los datos generados hasta el momento se plantea un escenario que lleva a la activación de la célula Th mediada por células de Langerhans en LC (figura 1). En tal contexto, luego de la inoculación del parásito por el vector, los macrófagos presentes en la dermis son parasitados rápidamente; luego, los parásitos extracelulares que se acumulan en el tejido de la lesión encuentran a las células de Langerhans que están transitando por la dermis (ya sea porque son constitutivas de la dermis o porque son reclutadas por mecanismos dependientes de quimiocinas) y son ingeridos por dichas células de Langerhans que transportan los antígenos a los ganglios linfáticos regionales drenantes de la lesión. En el ganglio linfático, las células de Langerhans presentan los antígenos derivados de Leishmania a las células T no sensibilizadas; no obstante, otras poblaciones de células dendríticas como las células dendríticas plasmocitoides pueden adquirir parásitos o antígenos del parásito provenientes de las células de Langerhans para presentarlos a las células $T$ ya que se ha observado un número aumentado de células dendríticas plasmocitoides en los ganglios linfáticos de ratones susceptibles a infección por L. (L) major y, a diferencia de las células de Langerhans que poseen altas cargas parasitarias, estas células dendríticas plasmocitoides tienen bajas cargas de parásitos pero con una infección más duradera, lo que garantiza un largo periodo de presentación del antígeno (107). De esta forma, las células de Langerhans, en colaboración con otras poblaciones de células dendríticas, inducen la activación y expansión de células T productoras de IFN- $\gamma$ lo que conlleva a la activación del macrófago, a la muerte de los parásitos en el interior del macrófago activado y, finalmente, a la involución de la lesión. Además, la interacción de las moléculas CD40-CD40L, la producción de IFNre IL-12, y la síntesis de oxido nítrico dependiente de iNOS son todos mecanismos necesarios para 
que la respuesta iniciada por las células de Langerhans concluya en el control de la enfermedad. Por otro lado, en condiciones adversas tales como un microambiente en el ganglio linfático caracterizado por citocinas tipo Th2, como IL-4 e IL-5, se puede desencadenar una respuesta mediada por células como eosinófilos y mastocitos que no favorece el control de la lesión sino, por el contrario, su exacerbación $(103,106,108,109)$.

\section{Conclusiones}

En esta revisión se abordaron las principales características de las células de Langerhans y los hallazgos obtenidos en modelos de interacción con los parásitos del género Leishmania. La información existente sugiere que en las infecciones por Leishmania las células de Langerhans participan activamente en la iniciación y regulación de la respuesta inmune específica gracias a su capacidad de migración y presentación antigénica, mientras que el macrófago parece estar más involucrado en la eliminación de la infección cuando es activado por las citocinas producidas por las células $T$ específicas luego de su interacción con las células de Langerhans. Debido a la variedad de especies de Leishmania y a las diferencias existentes en las formas clínicas de la enfermedad producidas por las diferentes especies, sería de gran utilidad en nuestro país estudiar la interacción de las células de Langerhans con la especie $L$. (V) panamensis, la responsable de la mayoría de los casos de leishmaniasis en Colombia y que tiende a producir infecciones crónicas, persistentes e,incluso, comprometer las mucosas. También cabe resaltar la importancia de hacer investigaciones en este campo con células humanas ya que el modelo murino de infección por $L$. (L) major no reproduce la enfermedad producida por la infección por $L$. (V) panamensis en el humano. Todas estas aproximaciones permitirán identificar los componentes inmunológicos que pueden regular la generación de una respuesta inmune protectora contra las especies de nuestro medio y así disponer de posibles blancos para una intervención de tipo inmunoterapéutico o inmunoprofiláctica que se refleje en una disminución en la morbilidad y en las pérdidas económicas que produce la enfermedad en las zonas endémicas de Colombia.

\section{Agradecimientos}

Los autores agradecen al Instituto para el Desarrollo de la Ciencia y Tecnología en Colombia, Colciencias (proyecto 1115-05-10130), a la Fundación para la Promoción de la Investigación y la Tecnología, Banco de la República (proyecto 1167) y al Comité para el Desarrollo de la Investigación de la Universidad de Antioquia, CODI (proyecto CPT-0110) por la financiación del proyecto de investigación que ha permitido iniciar y desarrollar la línea de investigación orientada a profundizar en el tema de la interacción células dendríticas y $L$. (V) panamensis.

Milena Zuluaga recibió una beca dentro del programa "Joven investigador" del Instituto para el Desarrollo de la Ciencia y Tecnología en Colombia, Colciencias, 2002-2003.

\section{Referencias}

1. Desjeux P. Human leishmaniasis: epidemiology and public health aspects. World Health Stat Q 1992;45:26772.

2. Vélez ID, Ospina S, Henao G, Lepape P, Correa M, Wolf $\mathbf{M}$, et al. Epidemiología de la leishmaniosis cutánea en San Roque, Antioquia. Bol Epidem Antioq 1987;12: 354-9.

3. Vélez ID, Wolff M, Valderrama R, Escobar JP, Osorio L. Community and enviromental risk factors associated with cutaneous leishmaniasis in Montebello, Antioquia, Colombia. En: Leishmaniasis control strategies: a critical evaluation of IDRC-supported research. IDCR publications 1991;1:261-74.

4. Agudelo S, Vélez ID. La leishmaniosis: aspectos clínico-epidemiológicos, diagnóstico, tratamiento y control. La Clínica y el Laboratorio 2000;9:145-65.

5. Osorio LE, Castillo CM, Ochoa MT. Mucosal leishmaniasis due to Leishmania (Viannia) panamensis in Colombia: clinical characteristics. Am J Trop Med Hyg 1998;59:49-52.

6. Vélez I, Agudelo S, Robledo S, Jaramillo L, Segura I, Soccol V, et al. Diffuse cutaneous leishmaniasis with mucosal involvement in Colombia, caused by an enzymatic variant of Leishmania panamensis. Trans $\mathrm{R}$ Soc Trop Med Hyg 1994;88:199.

7. Corredor A, Kreutzer RD, Tesh RB, Boshell J, Paláu MT, Cáceres E, et al. Distribution and etiology of leishmaniasis in Colombia. Am J Trop Med Hyg 1990;42:206-14. 
8. Saravia NG, Weigle K, Navas C, Segura I, Valderrama L, Valencia AZ, et al. Heterogeneity, geographic distribution, and pathogenicity of serodemes of Leishmania Viannia in Colombia. Am J Trop Med Hyg 2002;66:738-44.

9. Ministerio de la Protección Social, Instituto Nacional de Salud. Situación epidemiológica de las enfermedades transmitidas por vectores, 2003-2004. SIVIGILA, Boletín Epidemiológico Semanal; 2004.

10. Vélez ID, Hendrickx E, Robledo SM, Agudelo S. Gender and cutaneous leishmaniasis in Colombia. Cad Saude Publica 2001;17:171-80.

11. Agudelo LA, Uribe J, Sierra D, Ruiz F, Vélez ID. Presence of American cutaneous leishmaniasis vectors surrounding the city of Medellin, Colombia. Mem Inst Oswaldo Cruz 2002;97:641-2.

12. Bejarano EE, Uribe S, Rojas W, Vélez ID. Phlebotomine sand flies (Diptera: Psychodidae) associated with the appearance of urban leishmaniasis in the city of Sincelejo, Colombia. Mem Inst Oswaldo Cruz 2002;97: 645-7.

13. Liew FY, O'Donnell CA. Immunology of leishmaniasis. Adv Parasitol 1993;32:161-259.

14. Robledo S, Wozencraft A, Valencia AZ, Saravia N. Human monocyte infection by Leishmania (Viannia) panamensis. Role of complement receptors and correlation of susceptibility in vitro with clinical phenotype. J Immunol 1994;152:1265-76.

15. Pearson RD, Harcus JL, Symes PH, Romito R, Donowitz GR. Failure of the phagocytic oxidative response to protect human monocyte-derived macrophages from infection by Leishmania donovani. J Immunol 1982;129:1282-6.

16. Blackwell JM. Regulation of Leishmania populations within the host. V. Resistance to $L$. donovani in wild mice. J Trop Med Hyg 1983;86:17-22.

17. Peters W, Killic-Kendrics R. Biology and epidemiology. En: Peters W, Killic-Kendrics R, editors. The leishmaniases in biology and medicine. London: Academic Press; 1987. p.1-120.

18. Scott P, Natovitz P, Coffman RL, Pearce E, Sher A. Immunoregulation of cutaneous leishmaniasis. T cell lines that transfer protective immunity or exacerbation belong to different $T$ helper subsets and respond to distinct parasite antigens. J Exp Med 1988;168:167584.

19. Locksley RM, Scott P. Helper T-cell subsets in mouse leishmaniasis: induction, expansion and effector function. Immunol Today 1991;12:A58-61.

20. Convit J, Ulrich M, Fernández CT, Tapia FJ, Caceres-Dittmar G, Castes M, et al. The clinical and immunological spectrum of American cutaneous leishmaniasis. Trans R Soc Trop Med Hyg 1993;87:444-8.
21. Pirmez C, Yamamura M, Uyemura K, Paes-Oliveira M, Conceicao-Silva F, Modlin RL. Cytokine patterns in the pathogenesis of human leishmaniasis. J Clin Invest 1993;91:1390-5.

22. Robledo S. Determinantes celulares de susceptibilidad a infección persistente y metastásica con Leishmania Viannia spp. (tesis). Medellín: Universidad de Antioquia; 1998.

23. Bosque F, Saravia NG, Valderrama L, Milon G. Distinct innate and acquired immune responses to Leishmania in putative susceptible and resistant human populations endemically exposed to L. (Viannia) panamensis infection. Scand J Immunol 2000;51:533-41.

24. Trujillo CM, Robledo SM, Franco JL, Vélez ID, Erb KJ, Patiño PJ. Endemically exposed asymptomatic individuals show no increase in the specific Leishmania (Viannia) panamensis-Th1 immune response in comparison to patients with localized cutaneous leishmaniasis. Parasite Immunol 2002;24:455-62.

25. Bogdan C, Gessner A, Solbach W, Ràllinghoff M. invasion, control and persistence of Leishmania parasites. Curr Opin Immunol 1996;8:517-25.

26. Lara ML, Layrisse Z, Scorza JV, Garcia E, Stoikow $\mathbf{Z}$, Granados $\mathrm{J}$, et al. Immunogenetics of human American cutaneous leishmaniasis, study of HLA haplotypes in 24 families from Venezuela. Hum Immunol 1991;30:129-35.

27. Solbach W, Moll H, Rollinghoff M. Lymphocytes play the music but macrophage calls the tune. Immunol Today 1991;12:4-6.

28. Moll H. Epidermal Langerhans cells are critical for immunoregulation of cutaneous leishmaniasis. Immunol Today 1993;14:383-7.

29. Andrade, ZA, Reed SG, Roters RB, Sadigursky M. Immunopathology of experimental cutaneous leishmaniasis. Am J Pathol 1984;114:137-48.

30. Will A, Blank C, Rollinghoff M, Moll H. Murine epidermal Langerhans cells are potent stimulators of a antigen-specific $\mathrm{T}$ cell response to Leishmania major the cause of cutaneous leishmaniasis. Eur J Immunol 1992;22:1341-7.

31. Gilchrist K, Robledo S. Las células dendríticas y su interacción con los parásitos de Leishmania. Acta Med Colomb 2003;28:117-26.

32. Croft M, Duncan DD, Swain SL. Response of naive antigen-specific CD4+ $T$ cells in vitro: characteristics and antigen-presenting cell requirements. J Exp Med 1992;176:1431-7.

33. Attanavanich K, Kearney JF. Marginal zone, but not follicular TB cells, are potential activators of naive CD4 T cells. J Immunol 2004;172:803-11.

34. von Bergwelt-Baildon MS, Vonderheide RH, Maeker B, Hirano N, Anderson KS, Butler MO et al. Human 
primary and memory cytotoxic $\mathrm{T}$ lymphocyte responses are efficiently induced by means of CD-40-activated B cells as antigen presenting cells: potential for clinical application. Blood 2002;99:3319-25.

35. Roth R, Gee RJ, Mamula MJ. B lymphocytes are autoantigen-presenting cells in the amplification of autoimmunity. Ann NY Acad Sci 1997;815:88-104.

36. Ronchese F, Hausmann B. B lymphocytes in vivo fail to prime naive $T$ cells but can stimulate antigenexperienced T lymphocytes. J Exp Med 1993;177:67990.

37. Moll H, Fuchs H, Blank C, Rollinghoff M. Langerhans cells transport Leishmania major from the infected skin to the draining lymph node for presentation to antigenspecific T cells. Eur J Immunol 1993;23:1595-601.

38. Inaba K, Steinman RM, van Voorhis WC, Muramatsu S. Dendritic cells are critical accessory cells for thymusdependent antibody responses in mouse and in man. Proc Natl Acad Sci USA 1983;80:6041-5.

39. Kitamura H, Iwakabe K, Yahata T, Nishimura S, Ohta A, Ohmi Y et al. The natural killer T (NKT) cell ligand alpha-galactosylceramide demonstrates its immunopotentiating effect by inducing interleukin (IL)-12 production by dendritic cells and IL-12 receptor expression on NKT cells. J Exp Med 1999;89:1121-8.

40. Brocker T, Riedinger M, Karjalainen K. Targeted expression of major histocompatibility complex (MHC) class II molecules demonstrates that dendritic cells can induce negative but not positive selection of thymocytes in vivo. J Exp Med 1997;185:541-50.

41. Shortman K, Liu YJ. Mouse and human dendritic cell subtypes. Nat Rev Immunol 2002;2:151-61.

42. Kripke ML, Munn CG, Jeevan A, Tang JM, Bucana C. Evidence that cutaneous antigen-presenting cells migrate to regional lymph nodes during contact sensitization. J Immunol 1990;145:2833-8.

43. Peguet-Navarro J, Dalbiez-Gauthier C, Rattis FM, van Kooten C, Banchereau J, Schmitt D. Functional expression of CD40 antigen on human epidermal Langerhans cells. J Immunol 1995;155:4241-7.

44. Moll H, Ritter U, Flohe S, Erb K, Bauer C, Blank C. Cutaneous leishmaniasis: a model for analysis of the immunoregulation by accessory cells. Med Microbiol Immunol (Berlin) 1996;184:163-8.

45. Steinman RM, Gutchinov B, Witmer MD, Nussenzweig MC. Dendritic cells are the principal stimulators of the primary mixed leukocyte reaction in mice. J Exp Med 1983;157:613-27.

46. Banchereau J, Briere F, Caux C, Davoust J, Lebecque S, Liu YJ, et al. Immunobiology of dendritic cells. Ann Rev Immunol 2000;18:767-811.

47. Banchereau J, Steinman MR. Dendritic cells and the control of immunity. Nature 1998;392:245-52.
48. Steinman RM, Inaba K. Myeloid dendritic cells. J Leukocyte Biol 1999;66:205-8.

49. Banyer J, Hapel AJ. Myb-transformed hematopoietic cells as a model for monocyte differenciation into dendritic cells and macrofages. J Leukoc Biol 1999;66: 217-23.

50. Chapuis F, Resenzwajg M, Yagello M, Ekman M, Biberfeld P, Gluckman JC. Differentiation of human dendritic cells from monocytes in vitro. Eur $\mathrm{J}$ Immunol 1997;27:431-41.

51. Palucka K, Taquet N, Sanchez-Chapuis F, Gluckman JC. Dendritic cells as the terminal stage of monocyte differentiation. J Immunol 1998;160:4587-95.

52. Cavanagh LL, Saal RJ, Grimmett KL, Thomas R. Proliferation in monocyte-derived dendritic cell cultures is caused by progenitor cells capable of myeloid differentiation. Blood 1998;92:1598-607.

53. Ardavín C. Thyminc dendritic cells. Immunol Today 1997; 18:352-61.

54. Santiago-Schwarz F. Positive and negative regulation of myeloid dendritic cell lineage. J Leukocyte Biol 1999; 66:209-19.

55. Rissoan MC, Soumelis V, Kadowaki N, Grouard G, Briere F, Malefyt R, et al. Reciprocal control of T helper cell and dendritic cell differentiation. Science 1999;283: 1183-6.

56. Vremec D, Pooley J, Hochrein H, Wu L, Shortman K. CD4 and CD8 expression by dendritic cell subtype in mouse thymus and spleen. J Immunol 2000;164:297886.

57. Ávila F, Sánchez C, Rivas A, Prado H, López JS. Alteración en la diferenciación de células dendríticas inmaduras humanas por adenocarcinomas pulmonares. Rev Inst Nal Enf Resp Mex 2002;15:135-42.

58. Blank C, Fuchs H, Rappersberger K, Rollinghoff M, Moll H. Parasitism of epidermal Langerhans cells in experimental cutaneous leishmaniasis with Leishmania major. J Infect Dis 1993;167:418-25.

59. Arnoldi J, Moll H. Langerhans cell migration in murine cutaneous leishmaniasis: regulation by tumor necrosis factor alpha, interleukin-1 beta, and macrophage inflammatory protein-1 alpha. Dev Immunol 1998;6:311.

60. von Stebut E, Belkaid Y, Jakob T, Sacks DL, Udey MC. Uptake of Leishmania major amastigotes results in activation and interleukin 12 release from murine skinderived dendritic cells: implications for the initiation of anti-Leishmania immunity. J Exp Med 1998;188:1547-52.

61. Moll H. The role of chemokines and accessory cells in the immunoregulation of cutaneous leishmaniasis. Behring Inst Mitt 1997;(99):73-8.

62. McDowell MA, Marovich M, Lira R, Braun M, Sacks D. Leishmania priming of human dendritic cells for CD40 
ligand-induced interleukin- 12 p70 secretion is strain and species dependent. Infect Immun 2002;70:3994-4001.

63. Pinchuk LM, Boyd BL, Kruger EF, Roditi I, Furger A. Bovine dendritic cells generated from monocytes and bone marrow progenitors regulate immunoglobulin production in peripheral blood B cells. Comp Immunol Microbiol Infect Dis 2003;26:233-49.

64. Moretta A. Natural killer cells and dendritic cells: rendezvous in abused tissues. Nat Rev Immunol 2002;2: 957-64.

65. Schuler G, Steinman RM. Murine epidermal Langerhans cells mature into potent immunostimulatory dendritic cells in vitro. J Exp Med 1985;161:526-46.

66. Romani N, Holzmann S, Tripp $\mathrm{CH}$, Koch F, Stoitzner P. Langerhans cells-dendritic cells of the epidermis. APMIS 2003;111:725-40.

67. Romani N, Ratzinger G, Pfaller K, Salvenmoser W, Stossel H, Koch F et al. Migration of dendritic cells into lymphatics-the Langerhans cell example: routes, regulation, and relevance. Int Rev Cytol 2001;207:23770 .

68. Romani N, Schuler G. The immunologic properties of epidermal Langerhans cells as a part of the dendritic cell system. Springer Semin Immunopathol 1992;13:26579.

69. Aiba S, Manome H, Yoshino Y, Tagami H. In vitro treatment of human transforming growth factor-beta1treated monocyte-derived dendritic cells with haptens can induce the phenotypic and functional changes similar to epidermal Langerhans cells in the initiation phase of allergic contact sensitivity reaction. Immunology 2000;101:68-75.

70. Tchou I, Sabido O, Lambert C, Misery L, Garraud $\mathbf{O}$, Genin C. Technique for obtaining highly enriched, quiescent immature Langerhans cells suitable for ex vivo assays. Immunol Lett 2003;86:7-14.

71. Kraal G, Breel M, Janse M, Bruin G. Langerhans' cells, veiled cells, and interdigitating cells in the mouse recognized by a monoclonal antibody. J Exp Med 1986; 163:981-97.

72. Sarmiento L, Peña S. La célula de Langerhans. Biomédica 2002;22:462-5.

73. Figdor CG, van Kooyk Y, Adema GJ. C-type lectin receptors on dendritic cells and Langerhans cells. Nat Rev Immunol 2002;2:77-84.

74. Steinman R, Hoffman L, Pope M. Maturation and migration of cutaneous dendritic cells. J Invest Dermatol 1995;105(Suppl.1):2S-7S.

75. Lenz A, Heine M, Schuler G, Romani N. Human and murine dermis contain dendritic cells. Isolation by means of a novel method and phenotypical and functional characterization. J Clin Invest 1993;92:2587-96.

76. Geissmann F, Prost C, Monnet JP, Dy M, Brousse $\mathrm{N}$, Hermine $\mathrm{O}$. Transforming growth factor beta1, in the presence of granulocyte/macrophage colonystimulating factor and interleukin 4 , induces differentiation of human peripheral blood monocytes into dendritic Langerhans cells. J Exp Med 1998;187: 961-6.

77. Anjuere F, del Hoyo GM, Martin P, Ardavin C. Langerhans cells develop from a lymphoid-committed precursor. Blood 2000;96:1633-7.

78. Ritter U, Melbner A, Schelding C, Körner H. CD8aand Langerin-negative dendritic cells, but not Langerhans cells, act as principal antigen-presenting cells in leishmaniasis. Eur J Immunol 2004;34:1-9.

79. Traver D, Akashi K, Manz M, Merad M, Miyamoto T, Engleman EG, Weissman IL. Development of CD8 alpha-positive dendritic cells from a common myeloid progenitor. Science 2000;290:2152-4.

80. Jakob T, Ring J, Udey MC. Multistep navigation of Langerhans/dendritic cells in and out of the skin. J Allergy Clin Immunol 2001;108:688-96.

81. Kimber I, Cumberbatch M. Stimulation of Langerhans cell migration by tumor necrosis factor alpha (TNFalpha). J Invest Dermatol 1992;99:48S-50S.

82. Cumberbatch M, Kimber I. Dermal tumour necrosis factor-alpha induces dendritic cell migration to draining lymph nodes, and possibly provides one stimulus for Langerhans' cell migration. Immunology 1992;75:25763.

83. Tang A, Udey MC. Inhibition of epidermal Langerhans cell function by low dose ultraviolet $B$ radiation. Ultraviolet $B$ radiation selectively modulates ICAM-1 (CD54) expression by murine Langerhans cells. J Immunol 1991;146:3347-55.

84. Enk AH, Angeloni VL, Udey MC, Katz SI. An essential role for Langerhans cell-derived IL-I beta in the initiation of primary immune responses in skin. J Immunol 1993;150:3698-704.

85. Cumberbatch M, Dearman RJ, Kimber I. Interleukin 1 beta and the stimulation of Langerhans cell migration: comparisons with tumour necrosis factor alpha. Arch Dermatol Res 1997;289:277-84.

86. Urban M. Cytokines and adhesion molecules in Graves' disease. Endokrynol Diabetol Chor Przemiany Materii Wieku Rozw 2000;6:5-9.

87. Santamaría LF. Las células de Langerhans en la inmunidad cutánea con especial referencia a la dermatitis atópica. Acta Dermatol 1998;3:173-81.

88. Cumberbatch M, Dearman RJ, Kimber I. Constitutive and inducible expression of interleukin- 6 by Langerhans cells and lymph node dendritic cells. Immunology 1996; 87:513-8

89. Ahuja SS, Mummidi S, Malech HL, Ahuja SK. Human dendritic cell (DC)-based anti-infective therapy: engineering DCs to secrete functional IFN-gamma and IL-12. J Immunol 1998;161:868-76. 
90. Fukao T, Tanabe M, Terauchi Y, Ota T, Matsuda S, Asano $\mathrm{T}$, et al. PI3K-mediated negative feedback regulation of IL-12 production in DCs. Nat Immunol 2002; 3:875-81.

91. Nestle FO, Alijagic S, Gilliet M, Sun Y, Grabbe S, Dummer R, et al. Vaccination of melanoma patients with peptide- or tumor lysate-pulsed dendritic cells. Nat Med 1998;4:328-32.

92. Semper AE, Heron K, Woollard AC, Kochan JP, Friedmann PS, Church MK, ReischI IG. Surface expression of Fc epsilon RI on Langerhans' cells of clinically uninvolved skin is associated with disease activity in atopic dermatitis, allergic asthma, and rhinitis. J Allergy Clin Immunol 2003;112:411-9.

93. Kraft S, Novak N, Katoh N, Bieber T, Rupec RA. Aggregation of the high-affinity IgE receptor $\mathrm{Fc}$ (epsilon)RI on human monocytes and dendritic cells induces NF-kappaB activation. J Invest Dermatol 2002; 118:830-7.

94. Jurgens M, Wollenberg A, Hanau D, de la Salle $\mathbf{H}$, Bieber T. Activation of human epidermal Langerhans cells by engagement of the high affinity receptor for IgE, Fc epsilon RI. J Immunol 1995;155:5184-9.

95. Reich K, Heine A, Hugo S, Blaschke V, Middel P, Kaser A, et al. Engagement of the Fc epsilon RI stimulates the production of IL-16 in Langerhans celllike dendritic cells. J Immunol 2001;167:6321-9.

96. Kraft S, Katoh N, Novak N, Koch S, Bieber T. Unexpected functions of FcepsilonRI on antigenpresenting cells. Int Arch Allergy Immunol 2001; 124:35-7.

97. Langeveld-Wildschut EG, Bruijnzeel PL, Mudde GC, Versluis C, van leperen-van Dijk AG, Bihari IC, et al. Clinical and immunologic variables in skin of patients with atopic eczema and either positive or negative atopy patch test reactions. J Allergy Clin Immunol 2000;105:1008-16.

98. Moll H, Flohe S, Rollinghoff M. Dendritic cells in Leishmania major-immune mice harbor persistent parasites and mediate an antigen-specific $T$ cell immune response. Eur J Immunol 1995;25:693-9.

99. Flohe S, Lang T, Moll H. Synthesis, stability, and subcellular distribution of major histocompatibility complex class II molecules in Langerhans cells infected with Leishmania major. Infect Immun 1997;65: 3444-50.

100. Mbow ML, DeKrey GK, Titus RG. Leishmania major induces differential expression of costimulatory molecules on mouse epidermal cells. Eur J Immunol 2001;31:1400-9.

101. Ponte-Sucre A, Heise D, Moll H. Leishmania major lipophosphoglycan modulates the phenotype and inhibits migration of murine Langerhans cells. Immunology 2001;104:462-7.

102. Inaba K, Metlay JP, Crowley MT, Steinman RM. Dendritic cells pulsed with protein antigens in vitro can prime antigen-specific, MHC-restricted T cells in situ. J Exp Med 1990;172:631-40. Errata en: J Exp Med 1990;172:1275.

103. Flohe SB, Bauer C, Flohe S, Moll H. Antigen-pulsed epidermal Langerhans cells protect susceptible mice from infection with the intracellular parasite Leishmania major. Eur J Immunol 1998;28:3800-11.

104. Scott P, Hunter CA. Dendritic cells and immunity to leishmaniasis and toxoplasmosis. Curr Opin Immunol 2002;14:466-70.

105. von Stebut E, Belkaid Y, Nguyen BV, Cushing M, Sacks DL, Udey MC. Leishmania major-infected murine Langerhans cell-like dendritic cells from susceptible mice release IL-12 after infection and vaccinate against experimental cutaneous leishmaniasis. Eur J Immunol 2000;30:3498-506.

106. Moll H, Scharner A, Kampgen E. Increased interleukin 4 (IL-4) receptor expression and IL-4-induced decrease in IL-12 production by Langerhans cells infected with Leishmania major. Infect Immun 2002; 70:1627-30.

107. Baldwin T, Henri S, Curtis J, O'Keeffe M, Vremec $\mathrm{D}$, Shormant $\mathrm{K}$, et al. Dendritic cell population in Leishmania major-infected skin and draining lymph nodes. Infect Immun 2004;72:1991-2001.

108. Solbach W, Laskay T. The host response to Leishmania infection. Adv Immunol 2000;74:275-317.

109. Udey MC, von Stebut E, Mendez S, Sacks DL, Belkaid Y. Skin dendritic cells in murine cutaneous leishmaniasis. Immunobiology 2001;204:590-4. 